\title{
L-ORNITHINE PHENYLACETATE ATTENUATES INCREASED ARTERIAL AND EXTRACELLULAR BRAIN AMMONIA AND PREVENTS INTRACRANIAL HYPERTENSION IN PIGS WITH ACUTE LIVER
}

\section{FAILURE}

\section{Lars Marius Ytrebø ${ }^{1, \S, *}$, Rune Gangsøy Kristiansen ${ }^{1}$, Hanne Mæhre ${ }^{2}$, Ole Martin

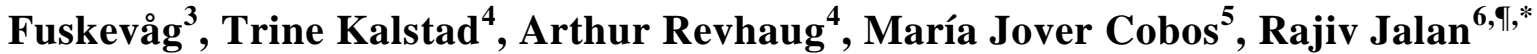 and Christopher F. Rose ${ }^{7, *}$}

1. Department of Anesthesiology, University Hospital of North Norway and University of Troms $\varnothing$, Norway

2. Institute of Marine Biotechnology, University of Troms $\emptyset$, Norway

3. Department of Clinical Pharmacology, University Hospital of North Norway and University of Troms $\emptyset$, Norway

4. Department of Digestive Surgery, University Hospital of North Norway and University of Troms $\emptyset$, Norway

5. Unit for Clinical Management of Digestive Diseases-CIBERehd, Hospital Universitario de Valme, Seville, Spain

6. Liver Failure Group, Institute of Hepatology, University College London Medical School, UK

7. Neuroscience Research Unit, Hôpital Saint-Luc (CRCHUM), Université de Montréal, Québec, Canada

${ }^{\dagger}$ Potential conflict of interest: University College London has filed for patents surrounding the use of L-Ornithine and Phenylacetate/Phenylbutyrate for the treatment of hepatic encephalopathy, which has been licensed to Ocera Therapeutics. ${ }^{\star}$ See Editorial on Page 3

\section{ABSTRACT}

Hyperammonemia is a feature of acute liver failure (ALF), which is associated with increased intracranial pressure (ICP) and brain herniation. We hypothesized that a combination of L-ornithine and phenylacetate (OP) would synergistically reduce toxic levels of ammonia by (1) L-ornithine increasing glutamine production (ammonia removal) through muscle glutamine synthetase and (2) phenylacetate conjugating with the ornithinederived glutamine to form phenylacetylglutamine, which is excreted into the urine. The aims of this study were to determine the effect of OP on arterial and extracellular brain ammonia concentrations as well as ICP in pigs with ALF (induced by liver devascularization). ALF pigs were treated with OP (L-ornithine $0.07 \mathrm{~g} / \mathrm{kg} / \mathrm{hour}$ intravenously; phenylbutyrate, prodrug for phenylacetate; $0.05 \mathrm{~g} / \mathrm{kg} /$ hour intraduodenally) for 8 hours following ALF induction. ICP was monitored throughout, and arterial and extracellular brain ammonia were measured along with phenylacetylglutamine in the urine. Compared with ALF + saline pigs, treatment with OP significantly attenuated concentrations of arterial ammonia (589.6 \pm 56.7 versus $365.2 \pm 60.4 \mu \mathrm{mol} / \mathrm{L}$ [mean \pm SEM], $\boldsymbol{P}=0.002)$ and extracellular brain ammonia $(\boldsymbol{P}=0.01)$. The ALF-induced increase in ICP was prevented in ALF + OP-treated pigs $(18.3 \pm 1.3 \mathrm{mmHg}$ in ALF + saline versus $10.3 \pm 1.1 \mathrm{mmHg}$ in ALF + OP-treated pigs $; \boldsymbol{P}=0.001)$. The value of ICP significantly correlated with the concentration of extracellular brain ammonia $\left(\boldsymbol{r}^{2}=0.36, \boldsymbol{P}<0.001\right)$. Urine phenylacetylglutamine levels increased to $4.9 \pm 0.6 \mu \mathrm{mol} / \mathrm{L}$ in ALF $+\mathrm{OP}$-treated pigs versus $0.5 \pm 0.04 \mu \mathrm{mol} / \mathrm{L}$ in $\mathrm{ALF}+$ saline-treated pigs $(\boldsymbol{P}<0.001)$.Conclusion: $\mathrm{L}-$ Ornithine and phenylacetate act synergistically to successfully attenuate increases in arterial ammonia, which is accompanied by a significant decrease in extracellular brain ammonia and prevention of intracranial hypertension in pigs with ALF. (HEPATOLOGY 2009;50:165-174.) 
This is the peer reviewed version of the following article: Ytrebø LM, Kristiansen RG, Maehre H, Fuskevåg OM, Kalstad T, Revhaug A, Cobos MJ, Jalan R, Rose CF. L-ornithine phenylacetate attenuates increased arterial and extracellular brain ammonia and prevents intracranial hypertension in pigs with acute liver failure. Hepatology 2009;50(1):165-174 which has been published in final form at http://dx.doi.org/10.1002/hep.22917

\section{Abbreviations}

ALF, acute liver failure; GS, glutamine synthetase; HE, hepatic encephalopathy; ICP, intracranial pressure; OP, L-ornithine phenylacetate.

\section{INTRODUCTION}

In patients with acute liver failure (ALF) increased intracranial pressure (ICP) leads to brain herniation, which accounts for $30 \%$ of deaths. ${ }^{1}$ Liver failure results in hyperammonemia, which leads to toxic levels of ammonia in the brain. In patients with ALF, an arterial ammonia level of $>150 \mu \mathrm{mol} / \mathrm{L}$ has been shown to correlate with severity of intracranial hypertension ${ }^{2}$ and deaths from brain herniation. ${ }^{3}$ More recently, ammonia levels were shown to be predictive of increased $\mathrm{ICP}^{4}$ and changes in blood ammonia concentration determined death due to cerebral edema in patients with ALF. ${ }^{5}$ Hence, ammonia-lowering strategies remain the primary therapeutic target for the treatment of increased ICP in ALF.

Studies focusing on ammonia metabolism in animal models and patients with liver failure indicate that the circulating levels of ammonia are regulated by a critical interplay of multiple organs, namely, the liver, muscles, kidney, and the small bowel, particularly in the context of liver disease. ${ }^{6,7}$ It has been shown that gut ammonia is primarily produced by the breakdown of glutamine in the small bowel through the action of the enzyme glutaminase. ${ }^{3,8,9}$ Many ammonia-lowering strategies have been directed toward reducing the production of ammonia in the gut, such as with nonabsorbable antibiotics and cathartics (nonabsorbable disaccharides). ${ }^{10} \mathrm{~A}$ recent meta-analysis concluded that there was a lack of evidence for the routine use of these strategies for the treatment of hepatic encephalopathy (HE) in patients with cirrhosis. ${ }^{11}$ No clinical trials have been performed with these strategies in patients with ALF. ${ }^{11,12}$ The preliminary results of a retrospective study from the U.S. liver failure group showed no effect of lactulose in ALF. ${ }^{13}$ Increasing ammonia detoxification as opposed to decreasing ammonia production has gained interest as an ammonia-lowering strategy. One approach is to increase the amount of substrates to stimulate ammonia-removing pathways such as glutamine synthetase (GS). GS, which is located in the brain, liver, and muscle, removes ammonia by aminating glutamate to form glutamine. The administration of the amino acids L-ornithine and L-aspartate to rats with ALF (hepatic devascularization) resulted in lowering of arterial ammonia and an increase in muscle GS activity. ${ }^{14}$ Here, Lornithine and L-aspartate transaminated to glutamate in the muscle and stimulated glutamine production through GS, lowering plasma ammonia. However, instead of being excreted through the kidneys, glutamine is capable of being metabolized in the gut or kidney and regenerating ammonia, causing an ammonia-rebound effect. ${ }^{15}$ Hence, the treatment of hyperammonemia and intracranial hypertension in ALF remains an unmet clinical need.

Phenylacetate is safe and effectively reduces ammonia concentration and improves survival of patients with urea cycle enzyme deficiencies. ${ }^{16-19}$ Phenylacetate lowers ammonia by reducing the substrate for ammoniagenesis (glutamine) through the formation of phenylacetylglutamine, which is excreted through the kidneys. ${ }^{16-18}$ The enhanced understanding of interorgan ammonia metabolism is the basis of the hypothesis in which the combination of L-ornithine and phenylacetate would act synergistically to increase excretion of ammonia in ALF (Fig. 1). ${ }^{15}$ Accordingly, the administration of L-ornithine would increase glutamine production through GS in muscle, thereby capturing one molecule of ammonia. Phenylacetate would conjugate this ornithine-derived glutamine, forming phenylacetylglutamine, which is excreted into the urine, thereby eliminating ammonia from the circulation. The aims of this study were to determine whether administration of L-ornithine phenylacetate (OP) reduces arterial ammonia and brain microdialysis ammonia and whether this reduction in ammonia is associated with an attenuation in ICP in our established porcine model of ALF (induced by hepatic devascularization), which develops typical clinical and biochemical features of ALF. ${ }^{20-23}$ 
This is the peer reviewed version of the following article: Ytrebø LM, Kristiansen RG, Maehre H, Fuskevåg OM, Kalstad T, Revhaug A, Cobos MJ, Jalan R, Rose CF. L-ornithine phenylacetate attenuates increased arterial and extracellular brain ammonia and prevents intracranial hypertension in pigs with acute liver failure. Hepatology 2009;50(1):165-174 which has been published in final form at http://dx.doi.org/10.1002/hep.22917

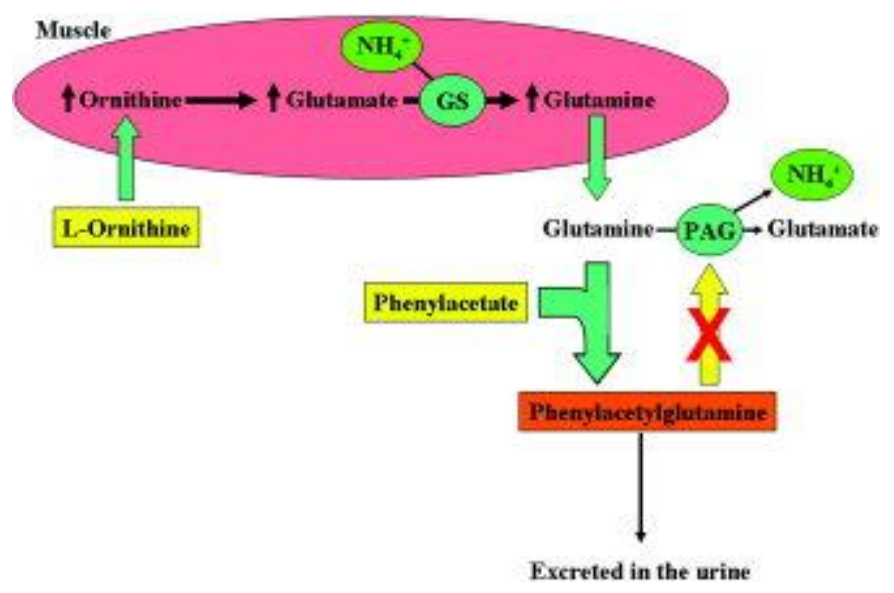

Figure 1. Hypothesis: The coadministration of L-ornithine and phenylacetate to pigs with ALF stimulates ammonia removal by increasing glutamate in the muscle (transamination of ornithine to glutamate) and increasing glutamine production through GS. Newly formed glutamine is thus conjugated with phenylacetate and excreted as phenylacetylglutamine through the kidneys, preventing a glutamine-induced ammonia rebound effect.

\section{MATERIALS AND METHODS}

\section{Study Outline.}

The study was performed in the Surgical Research Laboratory at the University of Troms $\varnothing$, Norway, and was approved by the Norwegian Experimental Animal Board. A well-validated and well-characterized large animal model was used..$^{20}$ The present study followed a pilot phase in which ALF pigs ( $\mathrm{n}=3$ each) were treated with placebo, L-ornithine $(0.07 \mathrm{~g} / \mathrm{kg} /$ hour intravenously), or phenylbutyrate (prodrug of phenylacetate; $0.05 \mathrm{~g} / \mathrm{kg} / \mathrm{hour}$ intraduodenally). Ammonia levels in the groups treated with either L-ornithine or phenylbutyrate alone were not different from the placebo-treated ALF group (see Supporting Fig. 1). Hence, the subsequent study was performed to evaluate the effect of OP. Twenty-four female pigs weighing 27-35 kg were randomized into three groups: sham-operated + vehicle $(\mathrm{n}=8) ;$ ALF + vehicle $(\mathrm{n}=8) ;$ ALF + L-Ornithine + Phenylbutyrate $(\mathrm{n}=8)$.

\section{Animal Preparation.}

The pigs were kept in the animal department for at least 2 days before the experiments. Details regarding the animal room facilities, anesthesia, surgical preparation, and routine management have been reported ${ }^{20,23}$ (see Supporting Material).

$\mathrm{T}=-30$ minutes was defined as the time when all catheters were in place, but before ALF induction (portacaval shunt + hepatic artery ligation). $\mathrm{T}=0$ hour was defined as the time of ALF induction or completion of abdominal surgery (sham-operated controls). At the end of the experiment ( $\mathrm{T}=8$ hours) the animals were sacrificed with lethal doses of potassium and pentobarbital.

\section{Administration of the Study Medication.}

L-ornithine was administered intravenously (Bufa Pharmaceuticals, Utgeest, The Netherlands) at a dose of 0.07 $\mathrm{g} / \mathrm{kg} /$ hour and phenylbutyrate (pro-drug for phenylacetate, Orphan Europe, Sweden) was administered intraduodenally at a dose of $0.05 \mathrm{~g} / \mathrm{kg} /$ hour and compared to pigs with ALF and shams. Medication was administered as a continuous infusion for the duration of the experiment starting at $\mathrm{T}=0$ and ending at $\mathrm{T}=8$ hours. Physiological saline $(9 \mathrm{mg} / \mathrm{mL})$ was used as vehicle in both the ALF and sham groups. All groups received an equal amount of fluids. 
This is the peer reviewed version of the following article: Ytrebø LM, Kristiansen RG, Maehre H, Fuskevåg OM, Kalstad T, Revhaug A, Cobos MJ, Jalan R, Rose CF. L-ornithine phenylacetate attenuates increased arterial and extracellular brain ammonia and prevents intracranial hypertension in pigs with acute liver failure. Hepatology 2009;50(1):165-174 which has been published in final form at http://dx.doi.org/10.1002/hep.22917

\section{Hemodynamic Monitoring.}

Cerebral: ICP monitoring has been described.23 Briefly, a burr hole was created over the right frontal region of the skull (1 cm lateral, $1 \mathrm{~cm}$ rostral from lambda), dura mater was incised, and a stable drift-free ICP transducer for continuous measurements (Codman MicroSensor; Johnson \& Johnson, Langhorne, PA) was inserted into the brain parenchyma $(0.5 \mathrm{~cm}$ ventral $)$. For microdialysis, another burr hole was created over the right frontal region ( $1 \mathrm{~cm}$ lateral, $2 \mathrm{~cm}$ rostral from lambda) of the skull and a microdialysis probe (CMA 70: $10 \mathrm{~mm}$ long semipermeable membrane (100,000 Da cutoff) was placed into the cortex $(0.25 \mathrm{~cm}$ ventral $)$ as described.21 The microdialysis catheter was connected to a microinjection pump (CMA/106 Microinjection pump; CMA Microdialysis, Stockholm, Sweden) and perfused with artificial CSF $\left(\mathrm{Na}^{+} 147 \mathrm{mM} ; \mathrm{K}^{+} 4 \mathrm{mM} ; \mathrm{Ca}^{+2} 2.3 \mathrm{mM} ; \mathrm{Cl}^{-}\right.$ $156 \mathrm{mM}$ ) at a flow rate of $3.0 \mu \mathrm{L} /$ minute. The microdialysate was collected every 1 hour, resulting in $180 \mu \mathrm{L}$ for biochemical analysis. Samples were stored at $-20^{\circ} \mathrm{C}$. At the end of the experiment a craniotomy was performed and the brain was removed, dissected, and examined for catheter placement and intracranial hemorrhage.

Cardiovascular: A 5F Edwards Swan-Ganz catheter (Baxter Healthcare, Irvine, CA) was floated into the pulmonary artery by way of the right external jugular vein. Cardiac output was measured in triplicate and the results expressed as the mean value (Vigilance, Edwards Lifesciences, Irvine, CA). The cardiac index was calculated as cardiac output/preoperative body weight. A 16G central venous catheter (Secalon T, Ohmeda, Swindon, UK) was introduced into the left external jugular vein for administration of drugs and fluids. Mean arterial pressure was measured in the left femoral artery, from which arterial blood samples were drawn. Cerebral perfusion pressure was calculated as mean arterial pressure-ICP. The urinary bladder was drained by way of a cystotomy.

\section{Blood and Cerebral Microdialysate Ammonia.}

Ammonia was measured as previously described. ${ }^{24}$ To quantify the concentration of ammonia measured in the microdialysate, using the same microdialysis probes and microperfusion pump (at a flow rate of $3.0 \mu \mathrm{L} / \mathrm{min}$ ), we measured the in vitro recovery rate of ammonia. This was done by immersing the probe in a solution with a known concentration of ammonia and measuring the concentration of ammonia in the collected microdialysate. The recovery rate at $3.0 \mu \mathrm{L} /$ minute was $41.2 \pm 5.4 \%$.

\section{Glutamine, Ornithine, and Urea.}

The determination of urea and physiological amino acids was performed as described by Dragnes et al. ${ }^{25}$ with some modifications (see Supporting Information).

\section{Muscle Glutamine Synthetase Activity.}

To measure GS activity we applied a modified version of the methods described25, 26 (see Supporting Information).

\section{Phenylacetylglutamine in Urine.}

Pig urine samples were prepared by adding $50 \mu \mathrm{L} 0.1 \mathrm{mM}$ phosphate buffer solution (pH 2.4) and $50 \mu \mathrm{L} 60 \mu \mathrm{M}$ internal standard (3-(4-hydroxyphenyl)propionic acid) to $50 \mu \mathrm{L}$ urine in a $4.5 \mathrm{~mL}$ polypropylene tube (Sarstedt, Germany). To the same tube, $1 \mathrm{~mL}$ tert-butyl methyl ether was added as the extractant. The tubes were capped, mixed by shaking for 1 minute, and centrifuged at $1,700 \mathrm{~g}$ for 180 seconds. Then $750 \mu \mathrm{L}$ of the supernatant was transferred to a second set of clean polypropylene tubes and evaporated to dryness under a stream of nitrogen at $40^{\circ} \mathrm{C}$. The residue was then reconstituted in $100 \mu \mathrm{L}$ mobile phase. Samples were analyzed by liquid chromatography-tandem mass spectrometry (LC/MS-MS) using Waters Acquity UPLC system with an autosampler and a binary solvent delivery system (Waters, Milford, MA) interfaced to a Waters Micromass Quattro Premier XE benchtop tandem quadrupole mass spectrometer (Waters, Manchester, UK). The system was controlled by MassLynx version 4.1. The chromatography was performed on a $2.1 \times 100 \mathrm{~mm}$ Waters Acquity 
This is the peer reviewed version of the following article: Ytrebø LM, Kristiansen RG, Maehre H, Fuskevåg OM, Kalstad T, Revhaug A, Cobos MJ, Jalan R, Rose CF. L-ornithine phenylacetate attenuates increased arterial and extracellular brain ammonia and prevents intracranial hypertension in pigs with acute liver failure. Hepatology 2009;50(1):165-174 which has been published in final form at http://dx.doi.org/10.1002/hep.22917

$\mathrm{BEH} \mathrm{C}_{18} 1.7 \mathrm{~mm}$ column. The mobile phase consisted of $50 \%$ methanol in $10 \mathrm{mM}$ aqueous formic acid with a flow rate of $0.2 \mathrm{~mL} /$ minute (isocratic).

\section{Statistical Analysis.}

Statistical analysis was performed using the Statistical Package for the Social Sciences, v. 14.0 for Windows (SPSS, Chicago, IL). Data are expressed as mean \pm standard error of the mean (SEM). Two-way analysis of variance (ANOVA) was applied to test for differences within and between groups over time. An overall significance in ANOVA for repeated measurements (F-test, $\boldsymbol{P} \leq 0.05$ ) may be attributable to either the effect of group $\left(\boldsymbol{P}_{\mathrm{G}}\right)$ or the interaction for group and time $\left(\boldsymbol{P}_{\mathrm{GT}}\right)$. Overall significance for the effect of group means that the groups were different when all the repeated measurements were taken together (independent of time), whereas a significant interaction denotes a different time course in the two groups. When significant interactions between the groups were found, simple contrast analyses were performed to identify at which specific timepoints the groups diverted from each other. Significance of difference between groups was tested by unpaired Student's $t$ test to evaluate GS activity data, total amount of phenylacetylglutamine formed, and percent change in extracellular brain ammonia. Correlation coefficients were assessed using the Spearman Rank Correlation Test (data was collected from all pigs at all timepoints). $\boldsymbol{P} \leq 0.05$ was considered significant for all tests applied.

\section{RESULTS}

One pig developed surgical complications and was excluded (ALF + OP group). Two pigs (one ALF and one sham pig) were excluded due to technical errors. Accordingly, data from 21 pigs (seven pigs in each group) were included in the present study.

\section{Ammonia.}

Eight hours following hepatic devascularization, arterial ammonia levels significantly increased from $30.6 \pm 4.7$ $\mu \mathrm{M}(\mathrm{T}=0)$ to $589.6 \pm 56.7 \mu \mathrm{M}(\mathrm{T}=8)$ in the ALF group, which was significantly attenuated in the ALF + OP treated group $\left(\mathrm{T}=0: 36.6 \pm 4.6 \mu \mathrm{M} ; \mathrm{T}=8: 365.2 \pm 60.4 \mu \mathrm{M}, \boldsymbol{P}_{\mathrm{GT}}=0.002\right)$. Arterial concentrations of ammonia remained unchanged in the sham group $(\mathrm{T}=0: 34.9 \pm 5.0 \mu \mathrm{M} ; \mathrm{T}=8: 50.7 \pm 8.7 \mu \mathrm{M})(\mathrm{Fig} .2 \mathrm{~A})$. Arterial concentrations of urea were significantly lower in the ALF group compared to sham-operated animals $\left(\boldsymbol{P}_{\mathrm{GT}}=\right.$ 0.021). There was no significant difference between ALF and ALF + OP treated animals $\left(\boldsymbol{P}_{\mathrm{G}}=0.08\right)$ (Fig. 2B). 
This is the peer reviewed version of the following article: Ytrebø LM, Kristiansen RG, Maehre H, Fuskevåg OM, Kalstad T, Revhaug A, Cobos MJ, Jalan R, Rose CF. L-ornithine phenylacetate attenuates increased arterial and extracellular brain ammonia and prevents intracranial hypertension in pigs with acute liver failure. Hepatology 2009;50(1):165-174 which has been published in final form at http://dx.doi.org/10.1002/hep.22917
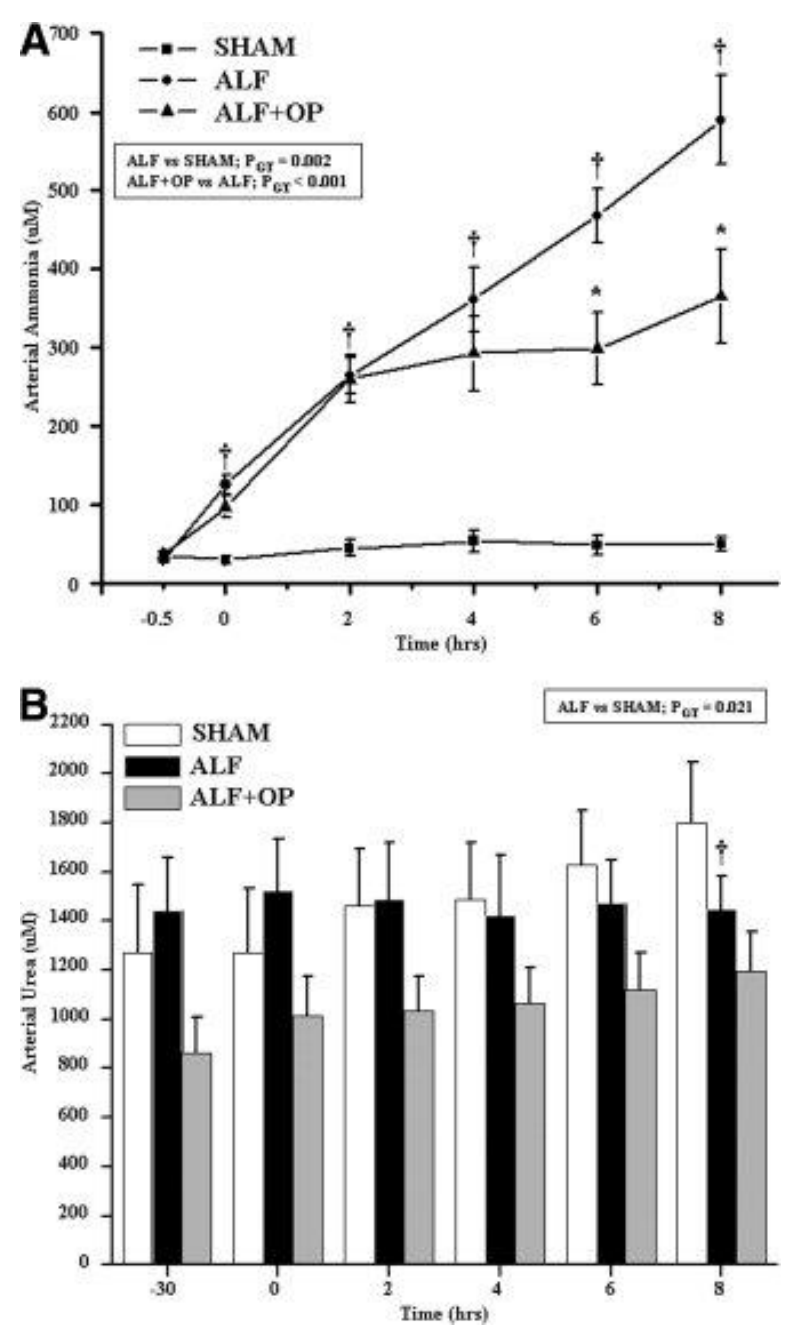

Figure 2. (A) Arterial ammonia concentrations over time: significant interaction between ALF versus sham $\left(\boldsymbol{P}_{\mathrm{GT}}=0.002\right)$ and ALF versus ALF + OP $\left(\boldsymbol{P}_{\mathrm{GT}}<0.001\right)$. (B) Arterial urea concentrations: significant interaction between ALF versus sham $\left(\boldsymbol{P}_{\mathrm{GT}}=0.021\right)$, no significant interaction ALF versus ALF + OP. Contrast analysis: †ALF versus sham, *ALF versus ALF + OP.

Cerebral microdialysate ammonia levels increased in the ALF animals from $\mathrm{T}=0: 91.5 \pm 39.0 \mu \mathrm{M}$ to $\mathrm{T}=8$ : $504.4 \pm 158.5 \mu \mathrm{M}$, which was attenuated significantly in the ALF + OP treated group $(\mathrm{T}=0: 52.8 \pm 10.4 \mu \mathrm{M} ; \mathrm{T}$ $\left.=8 ; 223.5 \pm 62.3 \mu \mathrm{M}, \boldsymbol{P}_{\mathrm{GT}}=0.01\right)$. Extracellular brain ammonia concentrations remained unchanged in the sham-operated animals $(\mathrm{T}=0: 36.9 \pm 4.3 \mu \mathrm{M} ; \mathrm{T}=8 ; 57.7 \pm 14.9 \mu \mathrm{M})$ (Fig. 3A). To emphasize the reduction in extracellular brain ammonia by OP, the percent increase from baseline is demonstrated in Fig. 3B. Using data from all nine timepoints, a significant positive correlation was found between arterial ammonia and extracellular brain ammonia $(\boldsymbol{r} 2=0.59, \boldsymbol{P}<0.001 ;$ Fig. $3 \mathrm{C})$. 
This is the peer reviewed version of the following article: Ytrebø LM, Kristiansen RG, Maehre H, Fuskevåg OM, Kalstad T, Revhaug A, Cobos MJ, Jalan R, Rose CF. L-ornithine phenylacetate attenuates increased arterial and extracellular brain ammonia and prevents intracranial hypertension in pigs with acute liver failure. Hepatology 2009;50(1):165-174 which has been published in final form at http://dx.doi.org/10.1002/hep.22917
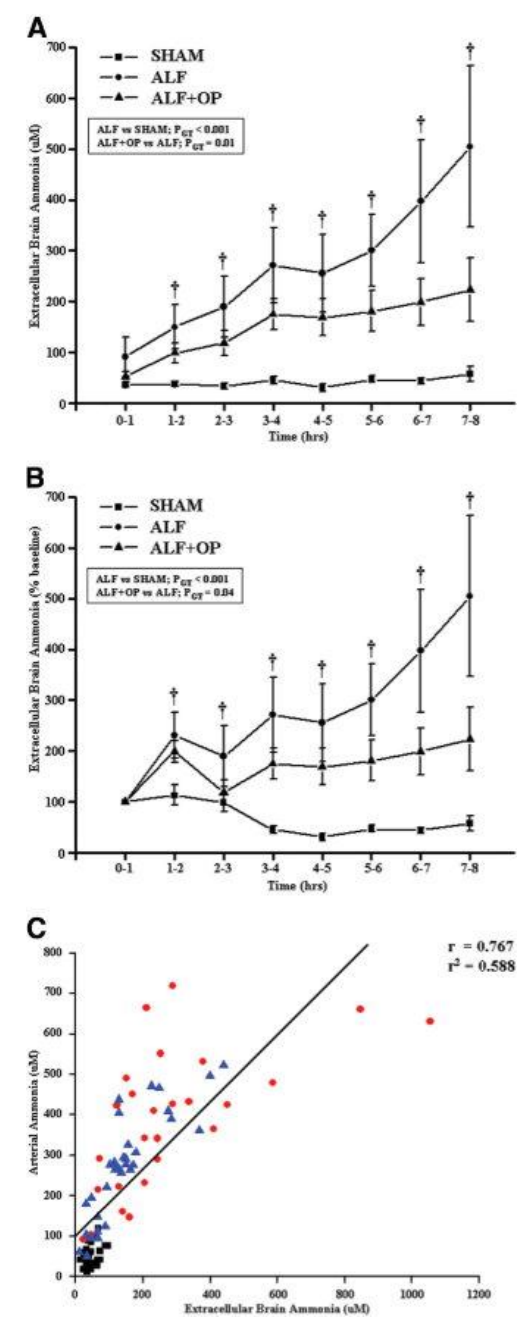

Figure 3. (A) Extracellular brain ammonia concentrations over time: significant interaction between ALF versus sham $\left(\boldsymbol{P}_{\mathrm{GT}}<0.001\right)$ and ALF versus ALF + OP $\left(\boldsymbol{P}_{\mathrm{GT}}=0.01\right)$. (B) Change in extracellular brain ammonia (expressed as percent baseline) over the duration of the study period in the three groups: significant interaction between ALF versus sham $\left(\boldsymbol{P}_{\mathrm{GT}}<0.001\right)$ and ALF versus $\mathrm{ALF}+\mathrm{OP}\left(\boldsymbol{P}_{\mathrm{GT}}=0.04\right)$. Contrast analysis: $\uparrow \mathrm{ALF}$ versus sham. $(\mathrm{C})$ Correlation between arterial ammonia and extracellular brain ammonia $(\boldsymbol{P}<0.001)(\bullet=\mathrm{SHAM}, \bullet=\mathrm{ALF}, \boldsymbol{\wedge}=\mathrm{ALF}+\mathrm{OP})$.

\section{Cerebrovascular Hemodynamics.}

ICP significantly increased from $6.6 \pm 0.6$ to $18.3 \pm 1.3 \mathrm{mmHg}$ in the ALF group. No significant change in ICP was observed over the study period in the ALF + OP treated animals $(\mathrm{T}=0: 6.1 \pm 0.4 \mathrm{mmHg} ; \mathrm{T}=8: 10.2 \pm 1.1$ $\left.\mathrm{mmHg}, \boldsymbol{P}_{\mathrm{GT}}=0.001\right)$. No changes in ICP were observed in the sham-operated group $(\mathrm{T}=0: 5.3 \pm 0.2 \mathrm{mmHg} ; \mathrm{T}$ $=8: 8.3 \pm 0.9 \mathrm{mmHg}$; Fig. 4A). Collecting all data, significant positive correlations were found between ICP and arterial ammonia $(\boldsymbol{r} 2=0.37, \boldsymbol{P}<0.001 ;$ Fig. $4 \mathrm{~B})$ and between ICP and extracellular brain ammonia $(\boldsymbol{r} 2=0.36, \boldsymbol{P}$ $<0.001$; Fig. 4C). 
This is the peer reviewed version of the following article: Ytrebø LM, Kristiansen RG, Maehre H, Fuskevåg OM, Kalstad T, Revhaug A, Cobos MJ, Jalan R, Rose CF. L-ornithine phenylacetate attenuates increased arterial and extracellular brain ammonia and prevents intracranial hypertension in pigs with acute liver failure. Hepatology 2009;50(1):165-174 which has been published in final form at http://dx.doi.org/10.1002/hep.22917
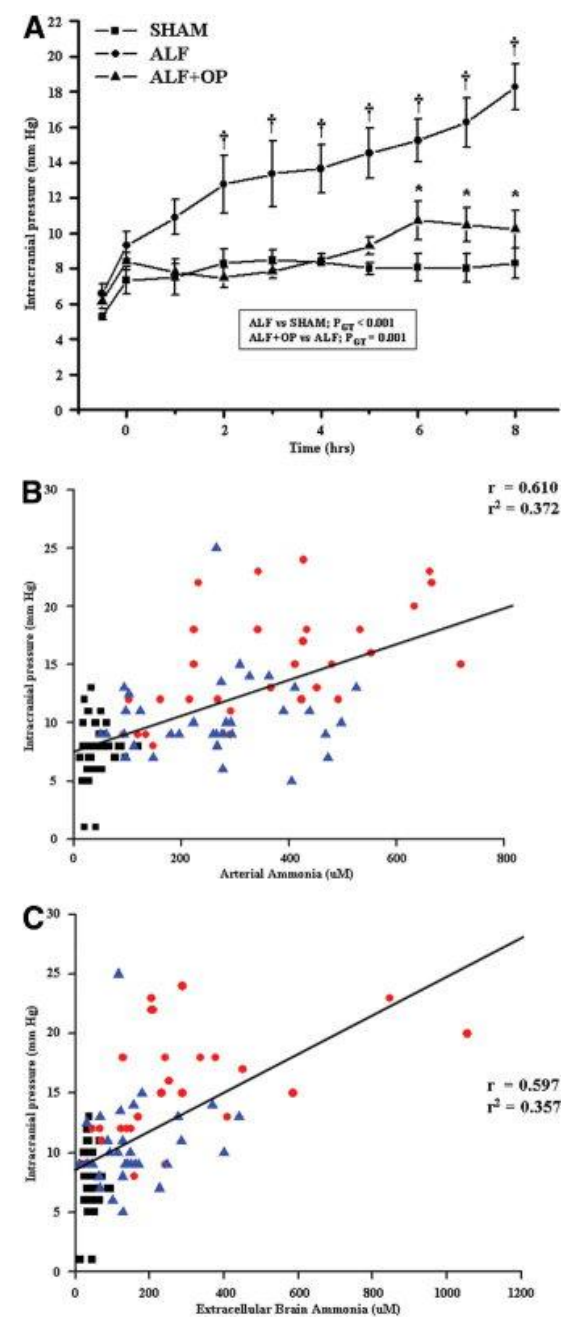

Figure 4. (A) ICP levels over time: significant interaction between ALF versus sham $\left(\boldsymbol{P}_{\mathrm{GT}}<0.001\right)$ and ALF versus ALF $+\mathrm{OP}\left(\boldsymbol{P}_{\mathrm{GT}}=0.001\right)$. Contrast analysis: $\dagger$ ALF versus sham, $*$ ALF versus ALF + OP. (B) Correlation between ICP and arterial ammonia $(\boldsymbol{P}<0.001)$. (C) Correlation between ICP and extracellular brain ammonia $(\boldsymbol{P}<0.001)(\bullet=\mathrm{SHAM}, \bullet=\mathrm{ALF}, \boldsymbol{\iota}=\mathrm{ALF}+\mathrm{OP})$.

\section{Cardiovascular Hemodynamics.}

Cardiac index increased in both the ALF and ALF + OP-treated groups, whereas it slightly decreased in the sham-operated group $\left(\boldsymbol{P}_{\mathrm{GT}}=0.01\right)$. Mean arterial pressure decreased over time in both the ALF and ALF + OPtreated groups, whereas it remained stable in the sham-operated group $\left(\boldsymbol{P}_{\mathrm{GT}}<0.001\right)$. Cerebral perfusion pressure was lower in the ALF and ALF + OP-treated groups compared to sham-operated controls $\left(\boldsymbol{P}_{\mathrm{GT}}<0.001\right)$, which remained unchanged throughout the experimental period (Table 1). 
This is the peer reviewed version of the following article: Ytrebø LM, Kristiansen RG, Maehre H, Fuskevåg OM, Kalstad T, Revhaug A, Cobos MJ, Jalan R, Rose CF. L-ornithine phenylacetate attenuates increased arterial and extracellular brain ammonia and prevents intracranial hypertension in pigs with acute liver failure. Hepatology 2009;50(1):165-174 which has been published in final form at http://dx.doi.org/10.1002/hep.22917

Table 1 Hemodynamic Variables in Sham-Operated $(n=7)$, ALF $(n=7)$, and ALF + OP $(n=7)$ Pigs

\begin{tabular}{|c|c|c|c|c|c|c|c|c|c|c|c|c|}
\hline \multirow[b]{2}{*}{ Variable } & \multicolumn{10}{|c|}{ Time } & \multirow{2}{*}{$\frac{P}{\begin{array}{c}\mathbf{T}=\mathbf{8} \\
\text { hrs }\end{array}}$} & \multirow[b]{2}{*}{$\begin{array}{c}P \\
P_{\mathrm{GT}}\end{array}$} \\
\hline & Group & $\begin{array}{c}T=-30 \\
\min \end{array}$ & $\begin{array}{c}\mathbf{T}=\mathbf{0} \\
\text { hrs }\end{array}$ & $\begin{array}{c}T=1 \\
\text { hrs }\end{array}$ & $\begin{array}{c}\mathbf{T}=2 \\
\text { hrs }\end{array}$ & $\begin{array}{c}\mathbf{T}=\mathbf{3} \\
\text { hrs }\end{array}$ & $\begin{array}{c}T=4 \\
\text { hrs }\end{array}$ & $\begin{array}{c}\mathbf{T}=\mathbf{5} \\
\mathrm{hrs}\end{array}$ & $\begin{array}{c}T=6 \\
\text { hrs }\end{array}$ & $\begin{array}{c}\mathbf{T}=7 \\
\mathrm{hrs}\end{array}$ & & \\
\hline \multirow[t]{3}{*}{$\operatorname{MAP}(\mathrm{mmHg})$} & Sham & $77 \pm 5$ & $78 \pm 5$ & $83 \pm 2$ & $98 \pm 3$ & $93 \pm 5$ & $86 \pm 6$ & $83 \pm 5$ & $82 \pm 7$ & $81 \pm 7$ & $85 \pm 7$ & \\
\hline & ALF & $82 \pm 6$ & $82 \pm 4$ & $75 \pm 3$ & $78 \pm 4$ & $75 \pm 3$ & $73 \pm 3$ & $69 \pm 1$ & $68 \pm 1$ & $67 \pm 2$ & $66 \pm 2$ & $<0.001$ \\
\hline & $A L F+O P$ & $81 \pm 5$ & $81 \pm 6$ & $77 \pm 6$ & $83 \pm 6$ & $73 \pm 5$ & $65 \pm 4$ & $60 \pm 4$ & $58 \pm 4$ & $57 \pm 4$ & $58 \pm 4$ & \\
\hline \multirow[t]{3}{*}{$\mathrm{Cl}(\mathrm{mL} / \mathrm{min} / \mathrm{kg})$} & Sham & $132 \pm 5$ & $140 \pm 10$ & $139 \pm 9$ & $128 \pm 8$ & $132 \pm 7$ & $111 \pm 19$ & $125 \pm 6$ & $119 \pm 7$ & $121 \pm 8$ & $114 \pm 7$ & \\
\hline & ALF & $132 \pm 10$ & $138 \pm 4$ & $116 \pm 20$ & $138 \pm 9$ & $146 \pm 4$ & $143 \pm 6$ & $153 \pm 5$ & $152 \pm 6$ & $148 \pm 8$ & $153 \pm 8$ & 0.01 \\
\hline & $A L F+O P$ & $144 \pm 11$ & $132 \pm 12$ & $120 \pm 15$ & $128 \pm 10$ & $135 \pm 9$ & $134 \pm 9$ & $134 \pm 7$ & $142 \pm 8$ & $142 \pm 8$ & $152 \pm 9$ & \\
\hline \multirow[t]{3}{*}{$\mathrm{CPP}(\mathrm{mmHg})$} & Sham & $72 \pm 5$ & $71 \pm 5$ & $75 \pm 2$ & $89 \pm 3$ & $84 \pm 5$ & $78 \pm 6$ & $75 \pm 5$ & $74 \pm 7$ & $73 \pm 7$ & $77 \pm 7$ & \\
\hline & ALF & $76 \pm 6$ & $73 \pm 4$ & $65 \pm 4$ & $67 \pm 5$ & $63 \pm 5$ & $61 \pm 3$ & $56 \pm 3$ & $55 \pm 3$ & $53 \pm 4$ & $50 \pm 4$ & $<0.001$ \\
\hline & $A L F+O P$ & $75 \pm 5$ & $73 \pm 6$ & $69 \pm 5$ & $75 \pm 5$ & $64 \pm 5$ & $54 \pm 4$ & $49 \pm 5$ & $48 \pm 4$ & $47 \pm 4$ & $48 \pm 4$ & \\
\hline
\end{tabular}

Values are mean \pm SEM.

\section{Glutamine and Ornithine.}

Arterial, muscle, and brain glutamine levels were significantly higher in ALF animals compared to shamoperated controls (Table 2). In the ALF + OP-treated animals, arterial glutamine levels were markedly higher $(\approx 300 \mu \mathrm{M})$ as were muscle glutamine levels $(\approx 360 \mu \mathrm{M})$ compared to the untreated ALF group. Brain glutamine levels were not significantly different in the ALF + OP animals compared with the untreated ALF group.

Although the muscle glutamine levels were similar in the ornithine-treated group compared with the ALF + OPtreated group, the arterial glutamine concentration was about $360 \mu \mathrm{M}$ less in the ALF + OP-treated group. Due to the fewer number of animals in the ornithine and phenylacetate alone groups, formal statistics were not possible to perform. In the OP-treated group there was a significantly higher concentration of the ornithine-treated ALF animals in the arterial plasma, muscle, and brain compared to ALF, indicating the bioavailability of the infused ornithine to the muscle. Similar results were found in the ornithine-treated animals (see Supporting Table 1). The muscle and brain ornithine levels were not significantly different between the ALF animals compared to shamoperated controls (Table 2).

Table 2. Glutamine and Ornithine Levels in Arterial Blood, Muscle, and Brain at $\mathrm{T}=\mathbf{8}$ Hours in Sham-Operated $(\mathrm{n}=7)$, $\operatorname{ALF}(n=7)$, and ALF + OP $(n=7)$ Pigs

\begin{tabular}{|c|c|c|c|c|c|c|}
\hline \multicolumn{4}{|c|}{ Glutamine } & \multicolumn{3}{|c|}{ Ornithine } \\
\hline & Arterial $(\mu \mathrm{mol} / \mathrm{L})$ & Muscle $(\mu \mathrm{mol} / \mathrm{kg})$ & Brain $(\mu \mathrm{mol} / \mathrm{kg})$ & Arterial $(\mu \mathrm{mol} / \mathrm{L})$ & Muscle ( $\mu \mathrm{mol} / \mathrm{kg})$ & Brain $(\mu \mathrm{mol} / \mathrm{kg})$ \\
\hline SHAM & $331 \pm 21$ & $1408 \pm 112$ & $7509 \pm 304$ & $71 \pm 4$ & $65 \pm 5$ & $22 \pm 2$ \\
\hline ALF & $672 \pm 52^{*}$ & $2475 \pm 106^{*}$ & $25582 \pm 1402^{*}$ & $174 \pm 16^{*}$ & $76 \pm 11$ & $27 \pm 5$ \\
\hline $\mathrm{ALF}+\mathrm{OP}$ & $973 \pm 104 \ddagger$ & $2831 \pm 124 \dagger$ & $23067 \pm 2561$ & $1200 \pm 66 \dagger$ & $611 \pm 87 \dagger$ & $100 \pm 8 \dagger$ \\
\hline
\end{tabular}

\section{Muscle Glutamine Synthetase Activity.}

Hindleg muscle GS activity tended to be higher in the ALF (19.1 $\pm 9.9 \mathrm{nU} / \mathrm{mg}$ protein; $115 \%$ higher than sham) and the ALF + OP groups ( $40.6 \pm 21.1 \mathrm{nU} / \mathrm{mg}$ protein; $356 \%$ higher than sham) compared with the shamoperated group ( $8.9 \pm 1.3 \mathrm{nU} / \mathrm{mg}$ protein), but these differences did not reach statistical significance (ALF versus sham, $\boldsymbol{P}=0.10$; ALF versus ALF + OP; $\boldsymbol{P}=0.82)($ Fig. 5$)$. 
This is the peer reviewed version of the following article: Ytrebø LM, Kristiansen RG, Maehre H, Fuskevåg OM, Kalstad T, Revhaug A, Cobos MJ, Jalan R, Rose CF. L-ornithine phenylacetate attenuates increased arterial and extracellular brain ammonia and prevents intracranial hypertension in pigs with acute liver failure. Hepatology 2009;50(1):165-174 which has been published in final form at http://dx.doi.org/10.1002/hep.22917

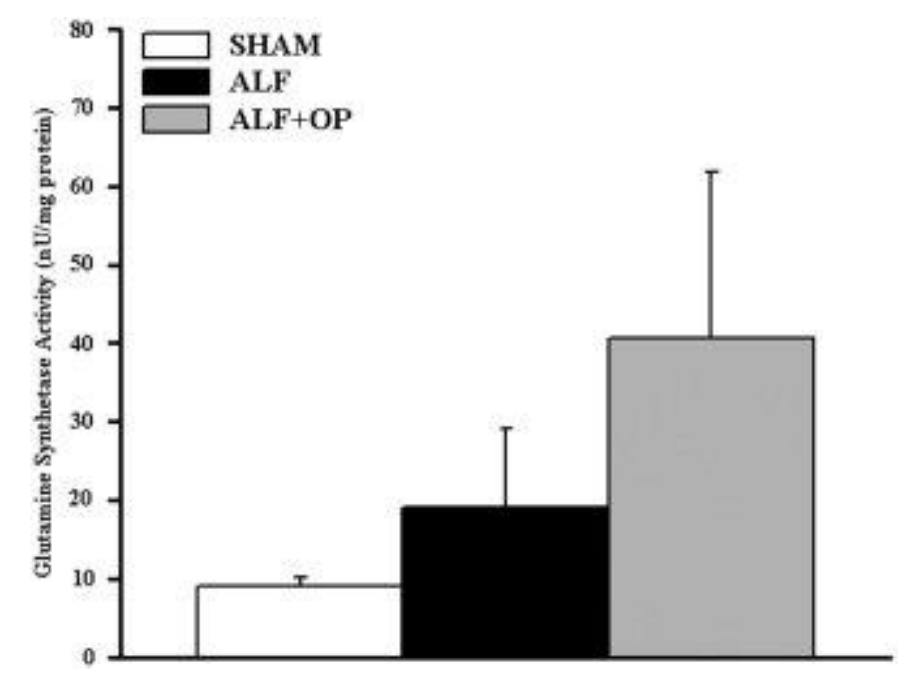

Figure 5. GS activity in hindleg skeletal muscle from sham-operated, ALF, and ALF + OP pigs.

\section{Urinary Phenylacetylglutamine.}

The concentration of phenylacetylglutamine increased significantly with time in the ALF + OP treated group (T $=8 ; 4.9 \pm 0.6 \mu \mathrm{mol} / \mathrm{L}$ ) compared to the untreated ALF group $\left(\mathrm{T}=8 ; 0.5 \pm 0.04 \mu \mathrm{mol} / \mathrm{L} ; \boldsymbol{P}_{\mathrm{GT}}<0.001\right)$ (Fig. 6).

The total amount of phenylacetylglutamine excreted (concentration $\times$ urine volume) was also significantly higher in ALF + OP-treated group ( $\mathrm{T}=8 ; 0.32 \pm 0.11 \mu \mathrm{mol})$ compared to the untreated ALF group $(0.02 \pm 0.01 \mu \mathrm{mol}$; $\boldsymbol{P}=0.04)$. No correlation was found between concentrations of phenylacetylglutamine in the urine and concentrations of ammonia in the blood (data not shown).

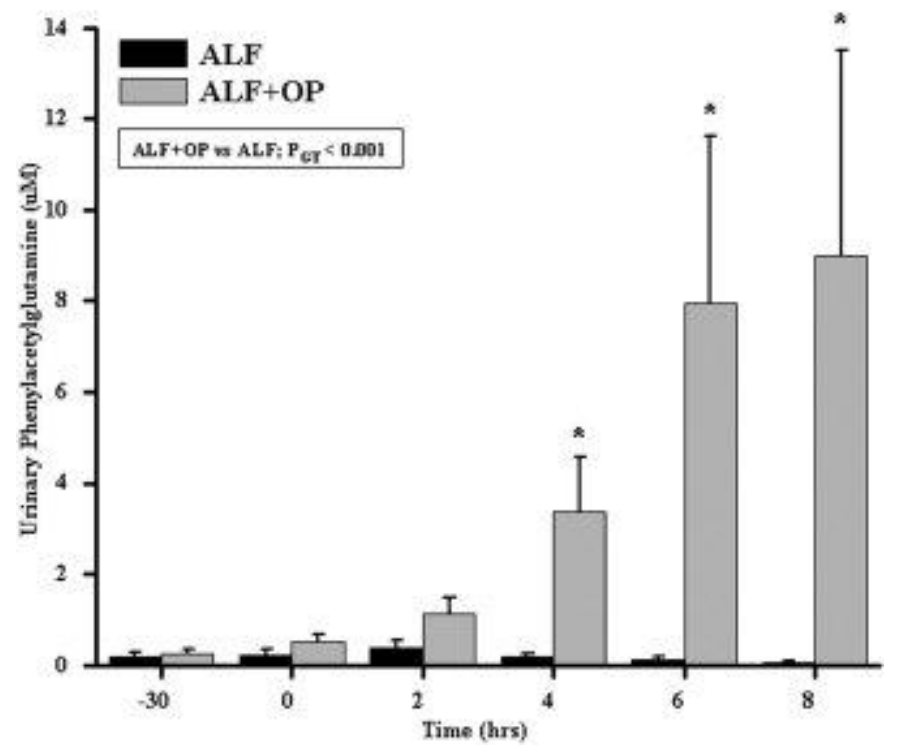

Figure 6. Urine concentrations of phenylacetylglutamine. Significant interaction between ALF and $\mathrm{ALF}+\mathrm{OP}\left(\boldsymbol{P}_{\mathrm{GT}}<0.001\right) . *$ Indicates contrast analyses $(\mathrm{ALF}$ versus ALF $+\mathrm{OP}), \boldsymbol{P}<0.05$. 
This is the peer reviewed version of the following article: Ytrebø LM, Kristiansen RG, Maehre H, Fuskevåg OM, Kalstad T, Revhaug A, Cobos MJ, Jalan R, Rose CF. L-ornithine phenylacetate attenuates increased arterial and extracellular brain ammonia and prevents intracranial hypertension in pigs with acute liver failure. Hepatology 2009;50(1):165-174 which has been published in final form at http://dx.doi.org/10.1002/hep.22917

\section{DISCUSSION}

The prevention and treatment of intracranial hypertension in patients with ALF remains an unmet clinical need. The hypothesis that ammonia is central in the pathogenesis of HE from over 100 years ago has been confirmed with several studies in the past 10 years pointing to the important relationship between arterial ammonia levels and the severity of cerebral edema, intracranial hypertension, and deaths related to brain herniation. ${ }^{2-5,27}$ The most important observation of this study was the demonstration that the combination of L-ornithine and phenylbutyrate (prodrug of phenylacetate), compounds that are already being used individually in humans, act synergistically to significantly attenuate the increase in arterial and cerebral microdialysis ammonia that is associated with a prevention of increased ICP in a liver devascularized model of ALF in the pig.

Many ammonia-lowering strategies have focused on lowering the production of ammonia in the large bowel using nonabsorbable disaccharides and antibiotics. Lactulose is commonly used in clinical practice but there is insufficient evidence to support whether it is beneficial in patients with $\mathrm{HE},{ }^{11}$ as its efficacy has yet to be proven in a high-quality randomized trial. Similarly, administrations of nonabsorbable antibiotics have not been proven to be an effective method of reducing ammonia or treating HE in patients with ALF. ${ }^{11}$ Another strategy to reduce the production of ammonia in the gut is by maintaining patients on a low-protein diet. This strategy was recently tested in a population of patients with cirrhosis but a low-protein diet was paradoxically shown to be deleterious, resulting in a catabolic state, increased protein breakdown, and no improvement in the severity of HE. ${ }^{28}$ Another ammonia-lowering strategy is to increase the capacity of ammonia detoxification. L-ornithine + L-aspartate given to patients with cirrhosis has been shown to be beneficial in lowering plasma ammonia and in improving the mental state of patients with early HE. ${ }^{29}$ Similar conclusions were found in L-ornithine + L-aspartate-treated portacaval shunted rats. ${ }^{30} \mathrm{~L}$-ornithine $+\mathrm{L}$-aspartate is thought to reduce the ammonia concentration by conversion of ammonia to glutamine by the enzyme GS in the muscle. ${ }^{14}$ However, more recently, observational studies in patients with liver failure demonstrated that the glutamine generated following administration of Lornithine $+\mathrm{L}$-aspartate was associated with a rebound hyperammonemia that could be prevented by administration of phenylacetate. ${ }^{15}$ This observation inspired investigators from the UK to propose a new hypothesis that involves coadministration of L-ornithine and phenylacetate that would increase ammonia removal through glutamine production (using L-ornithine) and preventing a glutamine-induced ammonia rebound (using phenylacetate). ${ }^{15}$

Our study was designed to test this hypothesis. Accordingly, during the pilot phase of our study the administration of either L-ornithine or phenylacetate individually did not have any significant effect on ammonia reduction but the combination worked synergistically to significantly attenuate an increase in ammonia (Supporting Fig. 1). In the OP-treated ALF animals, concentrations of ammonia in the arterial blood were reduced by $38 \%$ (at $\mathrm{T}=8$ ) compared to the untreated ALF animals. In order to monitor changes in concentrations of brain ammonia over time, a microdialysis catheter was placed in the frontal cortex. An increase in extracellular brain ammonia was observed over the experimental period in pigs with ALF, which was significantly prevented in ALF + OP-treated animals. A significant correlation between arterial ammonia and extracellular brain ammonia was demonstrated, supporting the fact that systemic hyperammonemia is associated with increased concentrations of ammonia in the brain. Brain tissue ammonia concentrations were not measured due to the unreliability of such measurements introduced by the relatively long time interval between the death of the animal, removal of the skull, and dissection of the brain, which could be as long as 15 minutes owing to the thickness of the pig skull. The reduction in arterial and microdialysis ammonia in the OP-treated ALF animals was associated with prevention of an increase in ICP that was not significantly different from shamoperated animals. In contrast, ICP increased by $121 \%$ in the untreated ALF animals compared to sham animals over an 8-hour period following hepatic devascularization. In this model, animals with ALF develop a hyperdynamic circulation with increased cardiac index and decreased mean arterial pressure. ${ }^{20,31}$ Cerebral perfusion pressure decreased in ALF pigs as a consequence of increased ICP and decreased mean arterial 
This is the peer reviewed version of the following article: Ytrebø LM, Kristiansen RG, Maehre H, Fuskevåg OM, Kalstad T, Revhaug A, Cobos MJ, Jalan R, Rose CF. L-ornithine phenylacetate attenuates increased arterial and extracellular brain ammonia and prevents intracranial hypertension in pigs with acute liver failure. Hepatology 2009;50(1):165-174 which has been published in final form at http://dx.doi.org/10.1002/hep.22917

pressure. Eight hours of OP treatment did not significantly affect the hemodynamics in pigs with ALF (Table 1), and therefore the prevention of increased ICP due to OP treatment in ALF animals is unlikely due to improved cerebral perfusion. In this model our previous studies have shown that the observed increase in ICP is independent of changes in cerebral blood flow. ${ }^{21}$

In our study we demonstrated a significant correlation between ICP and arterial concentrations of ammonia, as well as between ICP and extracellular concentrations of brain ammonia. Additionally, we observed a significant correlation between ICP and extracellular concentrations of brain ammonia. The importance of extracellular brain ammonia in the pathogenesis of intracranial hypertension highlighted in this study confirms our recent observation where a prevention in increased ICP using extracorporeal albumin dialysis was associated with a decrease in extracellular cerebral ammonia and not arterial ammonia. ${ }^{21,24}$ Although previous studies have clearly shown that hyperammonemia is associated with brain edema in humans and model systems, data aimed at treatment of hyperammonemia showing direct effects on the brain have been lacking. Our data provide novel evidence that reduction in systemic ammonia does indeed result in prevention of increased ICP, firmly emphasizing ammonia as an important central therapeutic target in ALF and HE.

Because there is no increased urea production in pigs with liver devascularization/ischemia (Fig. 2B), this is an excellent model of ALF to test ammonia-lowering strategies that are independent of the urea cycle. There was a strong trend toward an increase in the muscle GS activity in both the ALF groups both demonstrating an increase in GS activity compared to sham animals but with an even further increase observed in the ALF + OP-treated animals. However, these results did not reach statistical significance. Importantly, the data suggest that OP can stimulate glutamine production through GS solely by increasing its substrate.

In both the ornithine alone and OP-treated groups, an increase in concentration of ornithine and glutamine was observed in the arterial plasma and muscle compared to ALF. The increase in glutamine was associated with a substantial and significant lowering of arterial ammonia in only the OP-treated animals. The difference in ammonia between the ornithine alone and the OP-treated groups was of the magnitude of $\approx 360 \mu \mathrm{M}$. Feedback GS inhibition due to glutamine may play an important role in understanding the synergistic effect of OP. This feedback inhibition may be relieved upon the removal of glutamine by glutaminase; however, this in turn produces ammonia and contributes to hyperammonemia. Removing glutamine by phenylacetate relieves GS inhibition, allowing for further glutamine production and ammonia removal and contributes to lowering blood ammonia. ${ }^{32-34}$ Our data suggest that OP treatment lowers ammonia systemically in ALF animals and subsequently attenuates the concentration of ammonia in the brain. However, whether OP has a direct effect in lowering ammonia in the brain needs to be further evaluated. Brain ornithine levels were also significantly elevated in both the ornithine alone and the OP-treated animals but this increase was only modest compared with the concentration of ornithine in the arterial plasma and muscle from the same animals. This therefore may indicate the ornithine concentrations detected in the brain may be a result from contamination from the elevated concentration of ornithine in the blood. In the brain, OP treatment resulted in a reduction in glutamine that did not reach statistical significance compared with the ALF group.

In support of the hypothesis based around combining L-ornithine and phenylacetate, we were able to show clearly an increase in the excretion of phenylacetylglutamine in the urine in ALF + OP-treated pigs compared to saline-treated ALF pigs. Concentrations of phenylacetylglutamine in the urine increased over time in ALF + OP. However, there was a lack of stoichiometry between the reduction in arterial ammonia concentration and the increase in urinary phenylacetylglutamine. This is likely to be due to differences in conjugation pathways between humans and pigs. In humans, phenylacetylglutamine is the main renal excretion product of the reaction between phenylacetate and glutamine, but in pigs this association is less clear, as there are a number of additional by-products of phenylacetate metabolism. ${ }^{35} \mathrm{It}$ is also possible that the $360 \mu \mathrm{M}$ difference in the arterial glutamine between ornithine alone and OP-treated ALF animals may be explained by the delay in excretion of the conjugate as observed in a study with OP in cirrhotic rats. ${ }^{36}$ 
This is the peer reviewed version of the following article: Ytrebø LM, Kristiansen RG, Maehre H, Fuskevåg OM, Kalstad T, Revhaug A, Cobos MJ, Jalan R, Rose CF. L-ornithine phenylacetate attenuates increased arterial and extracellular brain ammonia and prevents intracranial hypertension in pigs with acute liver failure. Hepatology 2009;50(1):165-174 which has been published in final form at http://dx.doi.org/10.1002/hep.22917

In this study the protocol involved the administration of L-ornithine and phenylacetate as a continuous infusion for the duration of the experiment ( 8 hours). The administration and dosage/ratio of L-ornithine and phenylacetate was based on pilot studies in this model and in rats with cirrhosis (data not shown). However, further work is needed in order to define the optimal dosage/ratio for this novel treatment concept and whether bolus infusion followed by continuous infusion would be a better alternative. As seen in Fig. 2, OP attenuated hyperammonemia 4 hours following the start of infusion. A bolus infusion would possibly shorten this period, erasing the delay due to the absorption time of phenylacetate from the gut. Furthermore, at the time when the present experiments were performed, phenylacetate was only available as an oral formulation (intragastric/intraduodenal use).

In conclusion, the administration of OP to pigs with ALF successfully reduces arterial and extracellular brain ammonia levels and as a result prevents any rise in ICP during the experimental period. Because both Lornithine and phenylacetate are already used in humans, this novel treatment concept might quickly be translated into a much-needed therapy for the prevention and the treatment of increased ICP in patients with ALF.

\section{Acknowledgements}

The authors thank Janne Andreassen, Monica Figenschou, Hege Hagerup, Harry Jensen, and Mehrdad Sobkhez for excellent technical support during the experiments as well as Tom Wilsgaard for excellent statistical advice. We thank Dr. S. Hodges and Dr. G. Wright who helped with the development of the experimental ideas leading up to this study. We thank the staff at the Department of Clinical Chemistry, University Hospital of North Norway, for help and support during the early phase of these experiments.

\section{REFERENCES}

1 Lee WM, Squires RH Jr, Nyberg SL, Doo E, Hoofnagle JH. Acute liver failure: summary of a workshop. HEPATOLOGY 2008; 47: 1401-1415.

2 Jalan R, Olde Damink SW, Hayes PC, Deutz NE, Lee A. Pathogenesis of intracranial hypertension in acute liver failure: inflammation, ammonia and cerebral blood flow. J Hepatol 2004; 41: 613-620.

3 Clemmesen JO, Larsen FS, Kondrup J, Hansen BA, Ott P. Cerebral herniation in patients with acute liver failure is correlated with arterial ammonia concentration. HEPATOLOGY 1999; 29: 648-653.

4 Bernal W, Hall C, Karvellas CJ, Auzinger G, Sizer E, Wendon J. Arterial ammonia and clinical risk factors for encephalopathy and intracranial hypertension in acute liver failure. HEPATOLOGY 2007; 46: 1844-1852.

5 Bhatia V, Singh R, Acharya SK. Predictive value of arterial ammonia for complications and outcome in acute liver failure. Gut 2006; 55: 98-104.

6 Olde Damink SW, Deutz NE, Dejong CH, Soeters PB, Jalan R. Interorgan ammonia metabolism in liver failure.

Neurochem Int 2002; 41: 177-188.

7 Olde Damink SW, Dejong CH, Deutz NE, Redhead DN, Hayes PC, Soeters PB, et al. Kidney plays a major role in ammonia homeostasis after portasystemic shunting in patients with cirrhosis. Am J Physiol Gastrointest Liver Physiol 2006; 291: G189-G194.

8 Olde Damink SW, Jalan R, Deutz NE, Redhead DN, Dejong CH, Hynd P, et al. The kidney plays a major role in the hyperammonemia seen after simulated or actual GI bleeding in patients with cirrhosis. HEPATOLOGY 2003; 37: 12771285 .

9 Olde Damink SW, Jalan R, Redhead DN, Hayes PC, Deutz NE, Soeters PB. Interorgan ammonia and amino acid metabolism in metabolically stable patients with cirrhosis and a TIPSS. HEPATOLOGY 2002; 36: 1163-1171.

10 Riordan SM, Williams R. Treatment of hepatic encephalopathy. N Engl J Med 1997; 337: 473-479.

11 Als-Nielsen B, Gluud LL, Gluud C. Non-absorbable disaccharides for hepatic encephalopathy: systematic review of randomised trials. BMJ 2004; 328: 1046.

12 Festi D, Vestito A, Mazzella G, Roda E, Colecchia A. Management of hepatic encephalopathy: focus on antibiotic therapy. Digestion 2006; 73( Suppl 1): S94-S101.

13 Alba A, Haj J, Angulo P, Lee W. Lactulose therapy in acute liver failure. J Hepatol 2002; 36: 33. 
This is the peer reviewed version of the following article: Ytrebø LM, Kristiansen RG, Maehre H, Fuskevåg OM, Kalstad T, Revhaug A, Cobos MJ, Jalan R, Rose CF. L-ornithine phenylacetate attenuates increased arterial and extracellular brain ammonia and prevents intracranial hypertension in pigs with acute liver failure. Hepatology 2009;50(1):165-174 which has been published in final form at http://dx.doi.org/10.1002/hep.22917

14 Rose C, Michalak A, Rao KV, Quack G, Kircheis G, Butterworth RF. L-ornithine-L-aspartate lowers plasma and cerebrospinal fluid ammonia and prevents brain edema in rats with acute liver failure. HEPATOLOGY 1999; 30: 636-640.

15 Jalan R, Wright G, Davies NA, Hodges SJ. L-Ornithine phenylacetate (OP): a novel treatment for hyperammonemia and hepatic encephalopathy. Med Hypotheses 2007; 69: 1064-1069.

16 Brusilow SW, Danney M, Waber LJ, Batshaw M, Burton B, Levitsky L, et al. Treatment of episodic hyperammonemia in children with inborn errors of urea synthesis. N Engl J Med 1984; 310: 1630-1634.

17 Smith I. The treatment of inborn errors of the urea cycle. Nature 1981; 291: 378-380.

18 Darmaun D, Welch S, Rini A, Sager BK, Altomare A, Haymond MW. Phenylbutyrate-induced glutamine depletion in humans: effect on leucine metabolism. Am J Physiol 1998; 274: E801-E807.

19 Enns GM, Berry SA, Berry GT, Rhead WJ, Brusilow SW, Hamosh A. Survival after treatment with phenylacetate and benzoate for urea-cycle disorders. N Engl J Med 2007; 356: 2282-2292.

20 Ytrebo LM, Nedredal GI, Langbakk B, Revhaug A. An experimental large animal model for the assessment of bioartificial liver support systems in fulminant hepatic failure. Scand J Gastroenterol 2002; 37: 1077-1088.

21 Sen S, Rose C, Ytrebo LM, Davies NA, Nedredal GI, Drevland SS, et al. Effect of albumin dialysis on intracranial pressure increase in pigs with acute liver failure: a randomized study. Crit Care Med 2006; 34: 158-164.

22 Ytrebo LM, Korvald C, Nedredal GI, Elvenes OP, Nielsen Grymyr OJ, Revhaug A. N-acetylcysteine increases cerebral perfusion pressure in pigs with fulminant hepatic failure. Crit Care Med 2001; 29: 1989-1995.

23 Ytrebo LM, Ingebrigtsen T, Nedredal GI, Elvenes OP, Korvald C, Romner B, et al. Protein S-100beta: a biochemical marker for increased intracranial pressure in pigs with acute hepatic failure. Scand J Gastroenterol 2000; 35: $546-551$. 24 Rose C, Ytrebo LM, Davies NA, Sen S, Nedredal GI, Belanger M, et al. Association of reduced extracellular brain ammonia, lactate, and intracranial pressure in pigs with acute liver failure. HEPATOLOGY 2007; 46: 1883-1892.

25 Dragnes BT, Larsen R, Ernsten MH, Maehre H, Elvevoll EO. Impact of processing on the taurine content in processed seafood and their corresponding unprocessed raw materials. Int J Food Sci Nutr 2008: 1-10.

26 Minet R, Villie F, Marcollet M, Meynial-Denis D, Cynober L. Measurement of glutamine synthetase activity in rat muscle by a colorimetric assay. Clin Chim Acta 1997; 268: 121-132.

27 Khan SA, Shah N, Williams R, Jalan R. Acute liver failure: a review. Clin Liver Dis 2006; 10: 239-258, vii-viii.

28 Cordoba J, Lopez-Hellin J, Planas M, Sabin P, Sanpedro F, Castro F, et al. Normal protein diet for episodic hepatic encephalopathy: results of a randomized study. J Hepatol 2004; 41: 38-43.

29 Staedt U, Leweling H, Gladisch R, Kortsik C, Hagmuller E, Holm E. Effects of ornithine aspartate on plasma ammonia and plasma amino acids in patients with cirrhosis. A double-blind, randomized study using a four-fold crossover design. J Hepatol 1993; 19: 424-430

30 Rose C, Michalak A, Pannunzio P, Therrien G, Quack G, Kircheis G, et al. L-ornithine-L-aspartate in experimental portalsystemic encephalopathy: therapeutic efficacy and mechanism of action. Metab Brain Dis 1998; 13: 147-157.

31 Ytrebo LM, Sen S, Rose C, Davies NA, Nedredal GI, Fuskevaag OM, et al. Systemic and regional hemodynamics in pigs with acute liver failure and the effect of albumin dialysis. Scand J Gastroenterol 2006; 41: 1350-1360.

32 Mignon M, Leveque L, Bonnel E, Meynial-Denis D. Does concomitant glucose and glutamine supplementation change the response of glutamine synthetase to fasting in healthy adult rats? Clin Nutr 2007; 26: 662-666.

33 Watford M, Darcy-Vrillon B, Duee PH. Dietary glutamine suppresses endogenous glutamine turnover in the rat.

Metabolism 2000; 49: 141-145.

34 Smith RJ, Larson S, Stred SE, Durschlag RP. Regulation of glutamine synthetase and glutaminase activities in cultured skeletal muscle cells. J Cell Physiol 1984; 120: 197-203.

35 Kasumov T, Brunengraber LL, Comte B, Puchowicz MA, Jobbins K, Thomas K, et al. New secondary metabolites of phenylbutyrate in humans and rats. Drug Metab Dispos 2004; 32: 10-19.

36 Davies NA, Wright G, Ytrebø LM, Stadlbauer V, Ole-Martin F, Zwingman C, et al. L-Ornithine and phenylacetate synergistically produces sustained reduction in ammonia and brain water in cirrhotic rats. HEPATOLOGY 2009; 49(in press). 